Article

\title{
Spent Coffee Grounds Valorization as Bioactive Phenolic Source Acquired Antifungal, Anti-Mycotoxigenic, and Anti-Cytotoxic Activities
}

\author{
Ahmed Noah Badr ${ }^{1, *(D)}$, Marwa M. El-Attar ${ }^{2}$, Hatem S. Ali ${ }^{3, *}$, Manal F. Elkhadragy ${ }^{4}$, Hany M. Yehia ${ }^{5,6}$ (D) \\ and Amr Farouk ${ }^{7}$
}

Citation: Badr, A.N.; El-Attar, M.M.; Ali, H.S.; Elkhadragy, M.F.; Yehia, H.M.; Farouk, A. Spent Coffee Grounds Valorization as Bioactive Phenolic Source Acquired Antifungal, Anti-Mycotoxigenic, and Anti-Cytotoxic Activities. Toxins 2022, 14, 109. https://doi.org/10.3390/ toxins14020109

Received: 3 January 2022

Accepted: 25 January 2022

Published: 31 January 2022

Publisher's Note: MDPI stays neutral with regard to jurisdictional claims in published maps and institutional affiliations.

Copyright: (c) 2022 by the authors Licensee MDPI, Basel, Switzerland. This article is an open access article distributed under the terms and conditions of the Creative Commons Attribution (CC BY) license (https:// creativecommons.org/licenses/by/ $4.0 /)$.
1 Food Toxicology and Contaminants Department, National Research Centre, Cairo 12622, Egypt

2 Radioisotopes Department, Nuclear Research Center, Atomic Energy Authority, Cairo 11787, Egypt; m.elattar@agr.asu.edu.eg

3 Food Technology Department, National Research Center, Cairo 12622, Egypt

4 Department of Biology, College of Science, Princess Nourah bint Abdulrahman University, P.O. Box 84428, Riyadh 11671, Saudi Arabia; mfelkhadragy@pnu.edu.sa

5 Food Science and Nutrition Department, College of Food and Agriculture Science, King Saud University, P.O. Box 2460, Riyadh 11451, Saudi Arabia; hanyehia@ksu.edu.sa

6 Food Science and Nutrition Department, Faculty of Home Economics, Helwan University, Cairo 11221, Egypt

7 Flavour and Aroma Chemistry Department, National Research Centre, Cairo 12622, Egypt; af.mansour@nrc.sci.eg

* Correspondence: an.badr@nrc.sci.eg (A.N.B.); haali@ksu.edu.sa (H.S.A.); Tel.: +20-1000327640 (H.S.A.)

\begin{abstract}
Spent coffee grounds (SCGs), which constitute $75 \%$ of original coffee beans, represent an integral part of sustainability. Contamination by toxigenic fungi and their mycotoxins is a hazard that threatens food production. This investigation aimed to examine SCGs extract as antimycotic and anti-ochratoxigenic material. The SCGs were extracted in an eco-friendly way using isopropanol. Bioactive molecules of the extract were determined using the UPLC apparatus. The cytotoxicity on liver cancer cells (Hep-G2) showed moderate activity with selectivity compared with human healthy oral epithelial (OEC) cell lines but still lower than the positive control (Cisplatin). The antibacterial properties were examined against pathogenic strains, and the antifungal was examined against toxigenic fungi using two diffusion assays. Extract potency was investigated by two simulated models, a liquid medium and a food model. The results of the extract showed 15 phenolic acids and 8 flavonoids. Rosmarinic and syringic acids were the most abundant phenolic acids, while apigenin-7-glucoside, naringin, epicatechin, and catechin were the predominant flavonoids in the SCGs extract. The results reflected the degradation efficiency of the extract against the growth of Aspergillus strains. The SCGs recorded detoxification in liquid media for aflatoxins (AFs) and ochratoxin A (OCA). The incubation time of the extract within dough spiked with OCA was affected up to $2 \mathrm{~h}$, where cooking was not affected. Therefore, SCGs in food products could be applied to reduce the mycotoxin contamination of raw materials to the acceptable regulated limits.
\end{abstract}

Keywords: antifungal; anti-mycotoxigenic; aflatoxins; cytotoxicity; degradation; detoxification; phenolic acids; flavonoids; spent coffee grounds; simulated media

\section{Introduction}

Food by-products represent a critical global issue, where it is accumulated, representing global health and environmental issues. Food production increases annually due to the rise in the manufactured food demand, and therefore, the by-product quantities were raised. According to Ghosh et al. [1], the estimated population in 2100 will exceed 12 billion, which means the necessity toward sustainable food production, intelligent management, and exploitation of food and agro-waste. However, the rise in quantities of food by-products can be used as raw materials for the bio-economy [2]. Coffee is globally consumed due 
to its fantastic taste and compatibility with consumers' ${ }^{\prime}$ preferences. During instant coffee processing, spent coffee grounds (SCGs) result as the main by-product obtained after steam extraction. The average weight of SCGs constitutes about $75 \%$ of the original coffee bean [3]. The global coffee production in $2020 / 2021$ is about 10.17 million metric tons, which means about 6.5 million tons of SCGs have resulted from extraction [4]. The valorization of the SCGs through their implementation in biogas, food, feed, cosmetic, pharmaceutical, soil composites, and electricity production has been referred to before [5].

The SCGs showed concerning bioactive components such as insoluble dietary fiber, polysaccharides, lipids, amino acids, proteins, alkaloids, phenolics, minerals, and volatile compounds [6]. The previous investigations have focused on the SCGs' bioactivity and their antioxidant [7], anti-inflammatory [8], dermatological, anti-melanogenesis [9], and metal scavenging properties [10]. The optimum conditions of solid/liquid SCGs-extraction using solvent systems to recover the antioxidant polyphenols were studied [11]. However, the eco-friendly solvent system that complies with the halal food market is steadily increasing and is required as a global trademark. Halal food laws are applied in several counties and communities, strictly prohibiting the use of haram (forbidden) animals or alcohol as a cause of intoxication [12].

The application of eco-friendly extraction may represent new characteristics for the gained extract. These characteristics could implement antibacterial, antifungal, and antiviral properties. Phenolic components can be found in a wide range of botanical meals and drinks (tea, coffee, and cocoa). The most prevalent phenolic molecules are coumarins, flavonoids, lignins, proanthocyanidins, and stilbenes $[13,14]$. The inactivation of enzyme synthesis and antibiofilm impact are two of the antifungal properties of phenolic molecules that have been widely reported $[15,16]$. Plants have antimutagens, antimicrobials, antioxidants, and anti-carcinogens to reduce mycotoxins' toxicity and genotoxicity $[17,18]$. Antioxidants preserve cell membranes and biomolecules [19].

Moreover, phytochemicals cause cytotoxicity in fungi by altering cell membrane permeability and functionality, suppressing cytoplasmic and mitochondrial enzymes, suppressing enzymes associated with the formation of cell wall components, and changing the cell compartments, osmotic, and redox balance [20]. The previous investigation pointed to the phenolic content of the plant extract as an effective agent to suppress the fungal growth, which leads to an antifungal impact with its application [20]. Again, the phenolic content of the plant extract could regulate the fungal metabolism to decrease mycotoxin production. In this regard, the extract existing within fungal media may provide preservation for the applied product.

The present study evaluated the SCGs phenolics' recovery utilizing an environmentally friendly, halal, and cost-effective extraction since isopropanol was applied under mild temperature conditions to preserve their activity. The antibacterial, antifungal, antimycotoxigenic, and cytotoxic activities of the SCGs isopropanol extract were evaluated to promote this by-product as a natural and inexpensive food preservative. The valorization of this by-product extract will recommend its application as a natural additive with safety properties.

\section{Results}

\subsection{Characterization of SCGs Phenolic and Flavonoids}

In this study, 15 phenolic acids and 8 flavonoids, in addition to caffeine (alkaloid), have been determined by UPLC in the SCGs isopropanol extract (Table 1). Rosmarinic and syringic acids were the most abundant phenolic acids in the isopropanol extract of the SCGs. In addition, the phenolic fractions of gallic, sinapic, and salicylic acids were recorded in the extract by valuable content. The phenolic acids of chlorogenic and caffeic manifested as nearby quantities in the isopropanol extract of the SCGs. Other important acids such as p-coumaric, ferulic, and vanillic have existed in small amounts. The SCGs extracted using isopropanol reflect a distinguished content of flavonoids, with the detection of eight compounds as shown in Table 1. Apigenin-7-glucoside, naringin, epicatechin, and catechin 
were significant in SCGs extract (Table 1). Notwithstanding, kaempferol, chrysin, quercetin, and rutin were detected in relatively low concentrations.

Table 1. Contents of phenolic acids, flavonoids, and caffeine determined in SCGs isopropanol extract.

\begin{tabular}{|c|c|c|c|}
\hline \multicolumn{4}{|c|}{ Phenolic Acid Contents of the SCGs Extract } \\
\hline Compound & $\begin{array}{l}\text { Quantities } \\
(\mu \mathrm{g} / \mathrm{g})\end{array}$ & Compound & $\begin{array}{l}\text { Quantities } \\
(\mu \mathrm{g} / \mathrm{g})\end{array}$ \\
\hline Gallic acid & $18.15 \pm 0.63$ & Sinapic acid & $17.05 \pm 0.54$ \\
\hline Protocatechuic acid & $0.82 \pm 0.04$ & (S)-(-)-rosmarinic acid & $0.92 \pm 0.02$ \\
\hline p-Hydroxybenzoic acid & $3.65 \pm 0.09$ & Ferulic acid & $3.64 \pm 0.17$ \\
\hline Gentisic acid & $8.6 \pm 0.13$ & Salicylic acid & $12.67 \pm 0.27$ \\
\hline Chlorogenic acid & $7.38 \pm 0.31$ & p-coumaric acid & $0.19 \pm 0.03$ \\
\hline Caffeic acid & $7.2 \pm 0.73$ & Cinnamic acid & $0.495 \pm 0.06$ \\
\hline Syringic acid & $64.14 \pm 0.83$ & (R)-(+)-rosmarinic acid & $176.43 \pm 1.27$ \\
\hline Vanillic acid & $0.47 \pm 0.06$ & - & - \\
\hline \multicolumn{4}{|c|}{ Flavonoid Contents of the SCGs Extract } \\
\hline Compound & $\begin{array}{c}\text { Quantities } \\
(\mu \mathrm{g} / \mathrm{g})\end{array}$ & Compound & $\begin{array}{c}\text { Quantities } \\
(\mu \mathrm{g} / \mathrm{g})\end{array}$ \\
\hline Catechin & $16.86 \pm 0.27$ & Quercetin & $1.38 \pm 0.05$ \\
\hline Epicatechin & $53.83 \pm 1.02$ & Apigenin-7-glucoside & $1717.04 \pm 3.54$ \\
\hline Rutin & $4.87 \pm 0.11$ & Kaempferol & $3.18 \pm 0.41$ \\
\hline Naringin & $74.49 \pm 0.69$ & Chrysin & $1.34 \pm 0.18$ \\
\hline \multicolumn{4}{|c|}{ Alkaloid Contents of the SCGs Extract } \\
\hline \multicolumn{2}{|c|}{ Compound } & \multicolumn{2}{|c|}{$(\mu \mathrm{g} / \mathrm{g})$} \\
\hline \multicolumn{2}{|c|}{ Caffeine } & \multicolumn{2}{|c|}{$208.93 \pm 2.05$} \\
\hline
\end{tabular}

The data were expressed as means \pm SEM (where $n=3$, LSD $=0.704, p \leq 0.05$ ); SEM: standard error means; LSD: least significant differences;.SCGs: spent coffee grounds,.

\subsection{Cytotoxic Impact of SCGs Isopropanol Extract}

The cytotoxic effects of the isopropanol extract on the viability of the HepG2 and OEC cell lines are presented in Table 2. Generally, the extract of SCGs showed some degree of cytotoxicity against the studied cells, reducing the cell viability percentage of the liver cancer cell line (HepG2) after treatment in comparison with healthy OEC cells, which indicated a selectivity of the studied extract, with the selectivity index (SI) 1.2 and 1.85 for the MTT 3-(4,5-Dimethylthiazol-2-yl)-2,5-Diphenyltetrazolium Bromide (MTT assay) (MTT) and the Sulforhodamine B colorimetric assay (SRB), respectively. The values obtained from the both assays of MTT and SRB assays were comparable. An SI value $(<1)$ means the sample could be toxic and is not possible to be used as an herbal drug. Compared to the positive control, SCGs isopropanol extract was lower than Cisplatin's reference drug (Table 2).

Table 2. Cytotoxic activity of SCGs isopropanol extract against HepG2 and OEC cell lines using MTT and SRB assays.

\begin{tabular}{cccc}
\hline Extract & Cell Lines & IC $_{\mathbf{5 0}}(\boldsymbol{\mu g} / \mathbf{m L})$ & SI \\
\hline \multirow{2}{*}{ Cisplatin } & HepG2 & 66.69 & 1.3 \\
\cline { 2 - 4 } & OEC & 87.69 & - \\
\hline $\begin{array}{c}\text { Isoprpanol extract } \\
\text { (MTT) }\end{array}$ & HepG2 & 112 & 1.2 \\
\cline { 2 - 4 } & OEC & 133.7 & - \\
\hline $\begin{array}{c}\text { Isopropanol extract } \\
\text { (SRB) }\end{array}$ & HepG2 & 94.03 & - \\
\cline { 2 - 4 } & OEC & 174.1 & 1.85 \\
\hline
\end{tabular}

For the MTT test: the value of the LSD was (4.542); $\mathrm{R}^{2}=0.9912$. For the SRB test: the value of the LSD was (3.139); $\mathrm{R}^{2}=0.995 ; \mathrm{IC}_{50}$ : the half-maximal inhibitory concentratio; SI: selectivity index. 


\subsection{Isopropanol Bacterial (Diffusion Assay)}

The SCGs' antibacterial effect was recorded as having a valuable inhibition against tested strains of pathogenic bacteria (Figure 1). The inhibition zones, which were recorded by the two applied assays, were close to each other, emphasizing the efficient antibacterial effect of the extract versus used strains of food pathogens. According to the results, E. coli was the more sensitive strain influenced by the SCGs extract. It is worth mentioning that the SCGs inhibitory effect influenced both positive and negative strains of bacterial pathogens.

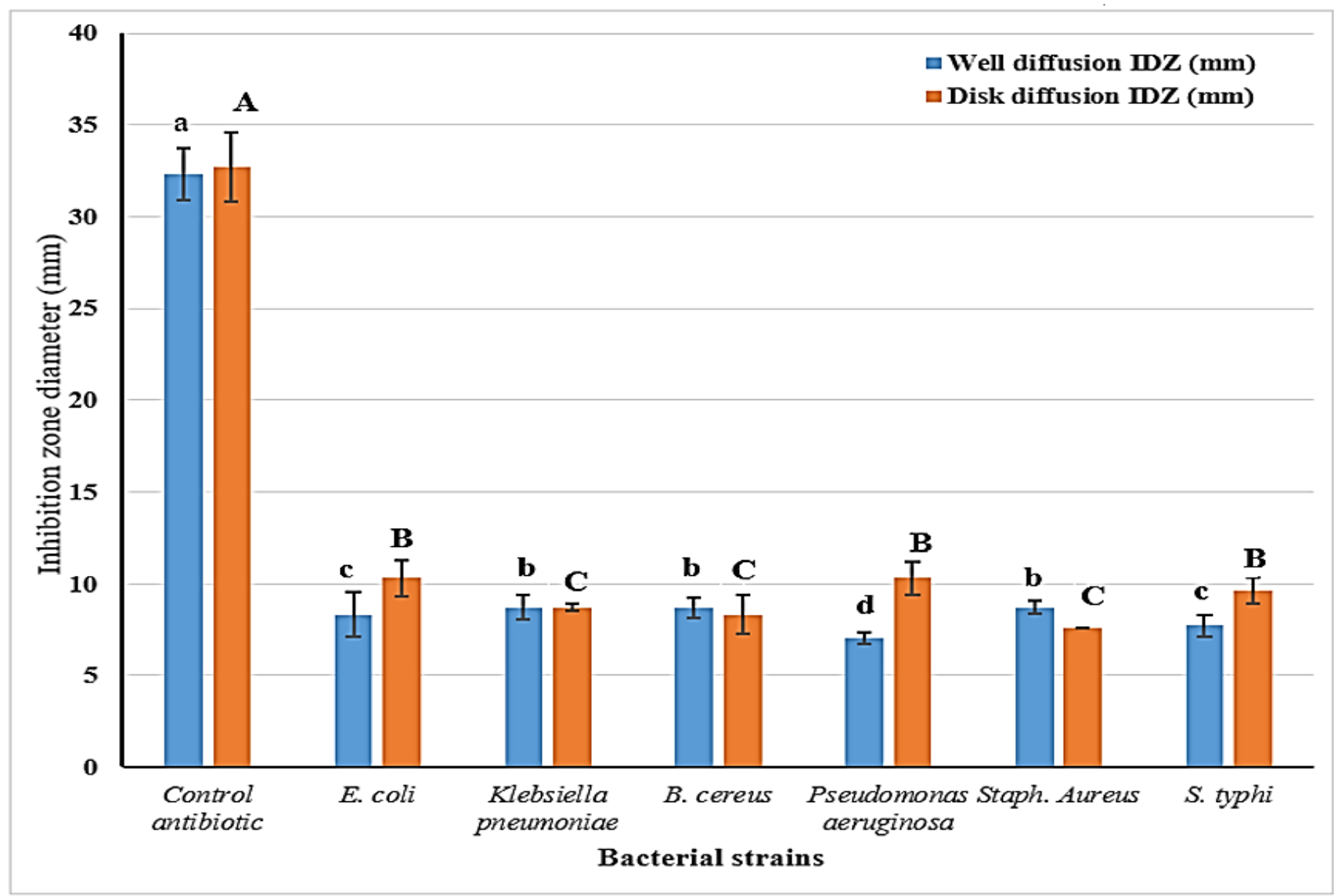

Figure 1. Antibacterial potency determined for the SCGs isopropanol extract against pathogenic strains of bacteria.

- The results are represented as means \pm SEM, where $(n=3 ;(p \leq 0.05)$; SEM: standard error means);

- IDZ: inhibition diameter of zone record. LSD: (0.577); letters are significantly different at $p \leq 0.05$ level: capitals for disk diffusion and small for the well diffusion assays.

The data represented in the following figure reflect that the significant differences were recorded between the strains as in small letters (for each assay). No considerable differences show the results for the well diffusion antibacterial assay of E. coli, Klebsiella, Bacillus, and Staphylococcus. Again, the disk diffusion antibacterial assay of the same strains manifested no significant differences.

The inhibition zone diameter of the extract was recorded in nearby values, using two antibacterial assays, for the strains Klebsiella and Bacillus, as pathogenic bacteria. Compared to the inhibition impact using the standard antibiotic compound, the extract was recorded to have an inhibition influence against the investigated strains of pathogenic bacteria. It is worth mentioning that, for some bacterial strains, the results regarding the two assays were shown by significant differences. The finding could recommend applying the SCGs extract to be an antibacterial agent in the manufacturing of several products. 


\subsection{Isopropanol Extract Antifungal (Diffusion Assay)}

Subsequently, the effect of the SCGs as an antifungal agent was evaluated against identified toxigenic strains of fungi known to produce mycotoxins. Tested strains mainly belonged to Aspergillus fungi, with two strains of Fusarium and Penicillium (Figure 2). The data represented the potency of the SCGs extract against the tested fungal strains, with a lower impact regarding the Penicillium strain. The extract's influence on the strains is known, with capacity for ochratoxin production (A. ochraceus, A. niger). Regarding the evaluation of the SCGs extract, it was recorded with a considerable content of phenolic compound (Table 1); this could have participated in the manifested antifungal effect. It is clear that the antifungal effect, which is reflected here as inhibition zone diameter, was demonstrated by antifungal influence against the investigated strains close to $50 \%$ of the standard antifungal impact.

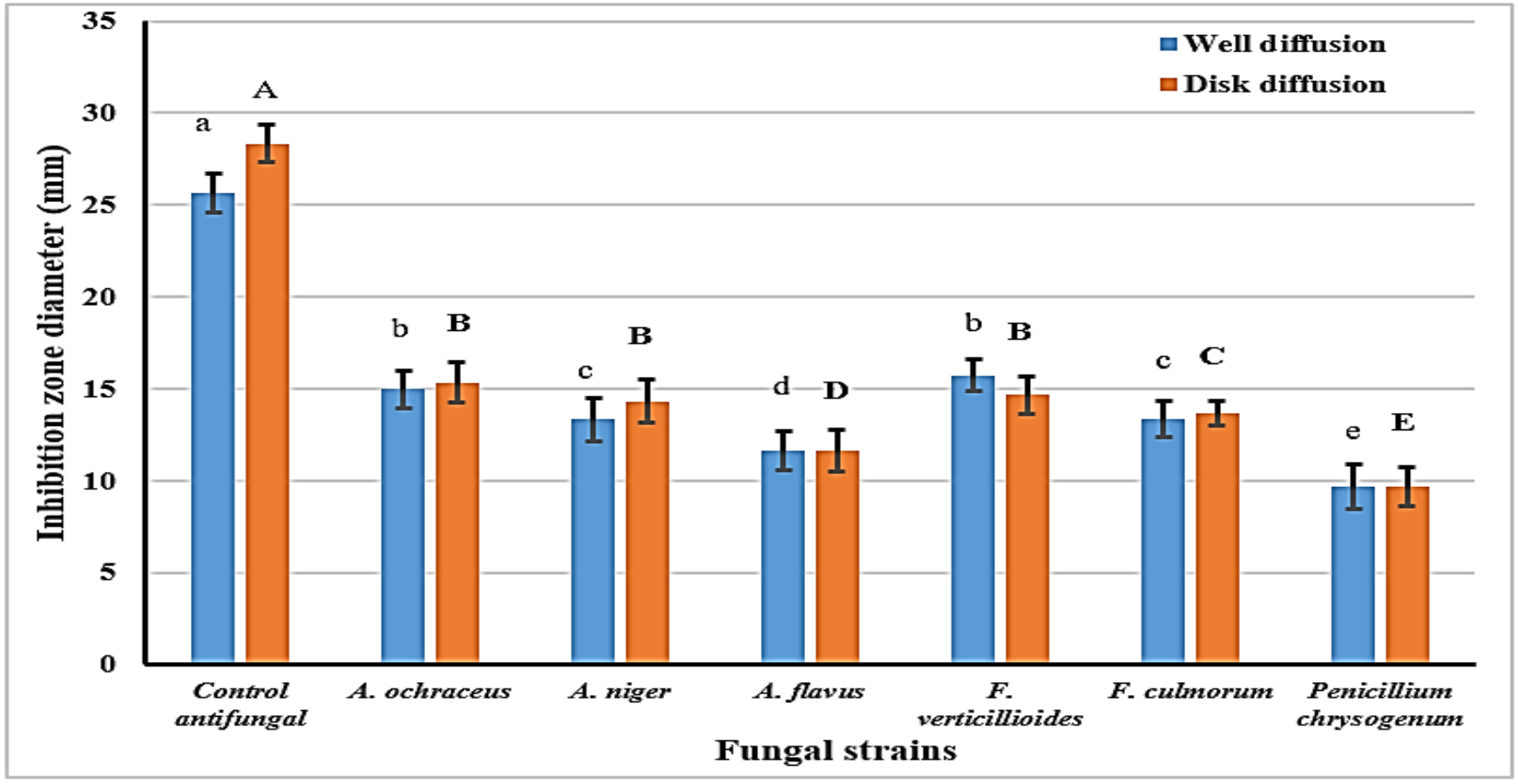

Figure 2. Antifungal impact determined for the SCGs isopropanol extract against toxigenic fungal strains using two assays.

- $\quad$ Results are represented as means \pm SEM, $(n=3 ; p \leq 0.05 ;$ LSD-0.701; SEM: standard error means).

- Letters are significantly different at $p \leq 0.05$ level: capitals for disk diffusion and small for the well diffusion assays.

\subsection{Simulation Growth Inhibition for Fungal-Producing Toxin Strains on Liquid Media}

To evaluate the reduction impact of the SCG to decrease the mycelial growth of two identified fungal-producing toxin strains, graduated concentrations of the SCG extract were applied in the liquid growth media of A. flavus and A. ochraceus. The results expressed in Figure 3 explain that the inhibition in the mycelia growth of fungi was raised by increasing the concentration of the extract. 


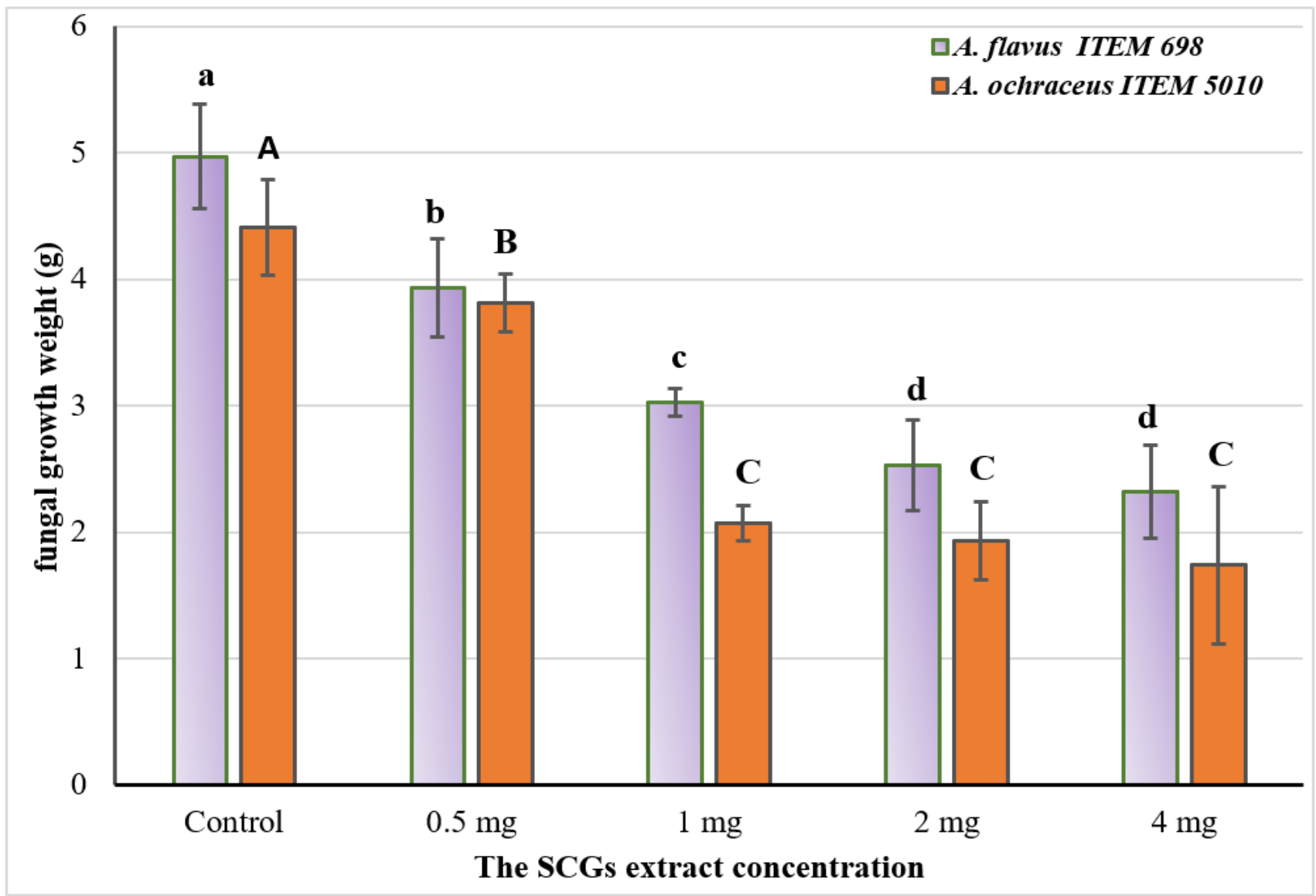

Figure 3. Reduction in fungal growth of two toxins producing Aspergillus strains using the SCGs extract.

- The results are represented as means \pm SEM, where $(n=3 ; p \leq 0.05) ; \mathrm{LSD}=0.397$; SEM: standard error means).

- Values labeled with different letters are significantly different at $p \leq 0.05$ level: capitals for $A$. ochraceus and smalls for $A$. flavus fungi. Upper and lower cases are for significant response of each strain to the treatment.

In this experiment, the authors aimed to simulate (using liquid media) the natural contamination that could happen by fungal strains known to have the capacity to produce mycotoxins. The positive impact of inhibition due to the SCGs extract indicates the extracts' efficacy as antimycotic material. Generally, these results referred to $1 \mathrm{mg} / \mathrm{mL}$ as mediated concentration with efficacy inhibition. The influence of extract to reduce the mycelia's fungal growth was significantly different between the investigated concentrations. It was reported that the values of the standard error mean at $1 \mathrm{mg}$ of the SCGs extract tested were shown in low weights, which could indicate the effect's stability. One more time, by the increment in extract concentration, the effect for the inhibition was raised, but the rate was lower for concentrations of more than $1 \mathrm{mg}$ extract/mL media.

\subsection{Simulation Degradation of Aflatoxins and Ochratoxin Production on Liquid Media}

The data represented in Table 3 describe the increment in toxin production limitation by the increase in the SCGs extract concentrations applied in fungal media. Utilizing the previous media of A. flavus ITEM 698 and A. ochraceus ITEM 5010 strains growth, the quantities of aflatoxins $\left(\mathrm{AFB}_{1}, \mathrm{AFB}_{2}, \mathrm{AFG}_{1}\right.$, and $\left.\mathrm{AFG}_{2}\right)$, as well as ochratoxin $\mathrm{A}(\mathrm{OCA})$, were determined. The results reflected that the greater the applied concentration of the SCGs extracts, the greater the toxin degradation ratio. However, more than $2 \mathrm{~mL} / \mathrm{mL}$ of media concentration was mainly recorded with no significant differences. 
Table 3. Reduction in aflatoxins and Ochratoxin A produced by Aspergillus toxin-producing strains using the graduated concentrations of the SCGs extract.

\begin{tabular}{cccccc}
\hline Concentration & AFB $_{\mathbf{1}}$ & $\mathbf{A F B}_{\mathbf{2}}$ & $\mathbf{A F G}_{\mathbf{1}}$ & AFG $_{\mathbf{2}}$ & OCA $^{\mathrm{a}}$ \\
\hline Control & $258.0 \pm 14.55^{\mathrm{a}}$ & $184.0 \pm 15.17^{\mathrm{a}}$ & $208.3 \pm 14.82^{\mathrm{a}}$ & $175.7 \pm 12.37^{\mathrm{a}}$ & $910.7 \pm 16.77^{\mathrm{a}}$ \\
0.5 & $194.3 \pm 13.09^{\mathrm{b}}$ & $138.3 \pm 13.81^{\mathrm{b}}$ & $174.3 \pm 14.26^{\mathrm{b}}$ & $148.0 \pm 12.19^{\mathrm{b}}$ & $612.6 \pm 17.05^{\mathrm{b}}$ \\
$1 \mathrm{mg}$ & $141.4 \pm 13.14^{\mathrm{c}}$ & $103.7 \pm 13.69^{\mathrm{c}}$ & $118.3 \pm 13.37^{\mathrm{c}}$ & $94.6 \pm 10.57^{\mathrm{c}}$ & $257.7^{\mathrm{c}} \pm 15.22^{\mathrm{c}}$ \\
$2 \mathrm{mg}$ & $132.0 \pm 12.88^{\mathrm{cd}}$ & $99.0 \pm 11.74^{\mathrm{cd}}$ & $103.6 \pm 12.07^{\mathrm{d}}$ & $86.3 \pm 11.77^{\mathrm{cd}}$ & $226.8 \pm 14.14^{\mathrm{d}}$ \\
$4 \mathrm{mg}$ & $119.3 \pm 16.23^{\mathrm{d}}$ & $88.3 \pm 11.81^{\mathrm{d}}$ & $98.7 \pm 12.54^{\mathrm{d}}$ & $79.0 \pm 11.41^{\mathrm{d}}$ & $201.0 \pm 13.79^{\mathrm{e}}$ \\
\hline
\end{tabular}

The results are represented as means $\pm \mathrm{SD}$, where $(n=3 ; p \leq 0.05)$; $\mathrm{SD}$ : Standard Deviation). $\mathrm{AFB}_{1}$ : aflatoxin $\mathrm{B}_{1} ; \mathrm{AFB}_{2}$ : aflatoxin $\mathrm{B}_{2} ; \mathrm{AFG}_{1}$ : aflatoxin $\mathrm{G}_{1} ; \mathrm{AFG}_{2}$ : aflatoxin $\mathrm{G}_{2} ; \mathrm{OCA}$ : ochratoxin $\mathrm{A}$. The values represented by different superscripted letters are significantly different for the same coulumn.

The data in Table 3 indicate the degradation that may happen for the active groups of mycotoxin molecules due to the bioactivity of the SCGs extract. It was noticed that the degradation ratio, which has been recorded regarding the OCA by the increment in extract concentration in the growth media of fungi, was higher than that recorded regarding aflatoxins (AFs).

\subsection{Application of the Spent on Brownies}

Ready-made brownie powder was fortified using several ratios of spent coffee; hence, it was spiked by ochratoxin $\mathrm{A}$, and mixes were evaluated for the incidence of toxin-content reduction. The results referred to incubation time and extract concentration in the dough as influential factors linked with ochratoxin reduction (Table 4). The removal of toxin amounts was observed by increasing the extract amount added to the dough ingredients. No significant difference was recorded for the OCA reduction in the dough after cooking. The reduction was significant at 3, 5, 7, and $10 \mathrm{mg}$ of extract applied in the dough between $0 \mathrm{~h}$ and after $2 \mathrm{~h}$ of incubation before the dough was baked. The reduction was significant for the concentration of the SCGs extract (1 $\mathrm{mg}$ and $10 \mathrm{mg}$ ) applied in the dough.

Table 4. Spiked Ochratoxin A reduction in a simulated model of contaminated brownies fortified by the SCGs extract.

\begin{tabular}{ccccccc}
\hline & Control & $\mathbf{1 ~ m g ~}^{*}$ & $\mathbf{3 ~ m g}^{*}$ & $\mathbf{5 ~ m g ~}^{*}$ & $\mathbf{7 ~ m g ~}^{*}$ & $\mathbf{1 0 ~ m g ~}^{*}$ \\
\hline Zero-time & $850 \pm 13.14^{\mathrm{a}}$ & $837 \pm 18.54^{\mathrm{a}}$ & $817 \pm 17.63^{\mathrm{a}}$ & $811 \pm 19.05^{\mathrm{a}}$ & $796 \pm 17.49^{\mathrm{a}}$ & $779 \pm 15.17^{\mathrm{a}}$ \\
2 h incubation & $852 \pm 14.56^{\mathrm{a}}$ & $742 \pm 13.79^{\mathrm{b}}$ & $711 \pm 19.13^{\mathrm{b}}$ & $671 \pm 18.21^{\mathrm{b}}$ & $524 \pm 17.71^{\mathrm{b}}$ & $319 \pm 27.64^{\mathrm{b}}$ \\
4 h incubation $^{\mathrm{a}}$ & $851 \pm 12.81^{\mathrm{a}}$ & $737 \pm 11.27^{\mathrm{b}}$ & $691 \pm 16.23^{\mathrm{b}}$ & $588 \pm 28.34^{\mathrm{c}}$ & $502 \pm 26.25^{\mathrm{b}}$ & $307 \pm 37.57^{\mathrm{b}}$ \\
After cooking $^{\mathrm{a}}$ & $836 \pm 17.37^{\mathrm{a}}$ & $731 \pm 10.91^{\mathrm{b}}$ & $689 \pm 15.84^{\mathrm{b}}$ & $574 \pm 27.77^{\mathrm{c}}$ & $495 \pm 26.84^{\mathrm{b}}$ & $282 \pm 33.93^{\mathrm{b}}$ \\
\hline
\end{tabular}

The results are represented as means $\pm \mathrm{SD}$, where $(n=3 ; p \leq 0.05$; SD: Standard Deviation). The values represented by different superscripted letters are significantly different. $\left(^{*}\right)$ refers to the concentration of spent extract applied in the dough.

\section{Discussion}

There are various undesirable properties, most notably the dose-related toxicity of chemical antifungals. Ideally, an antifungal should have null or reduced toxicity toward human cells [21]. Antifungal agents have reported drug resistance [22,23]. Therefore, it is necessary to discover new antifungal agents or safer alternatives to improve treatment against toxigenic fungi infection. In this regard, antifungal agents based on natural resources, such as phenolic compounds, are an alternative strategy to negate the rising antifungal drug resistance [24].

The phenolic compounds present in the SCGs are from the polyphenol-esters family, which mainly possesses bioactive functions including antioxidant, antibacterial, hepatoprotective, hypoglycemic, anticancer, and antiviral activities [6]. The bioactive molecules isolated from the SCGs have been reported to possess potential benefits as ingredients for the pharmaceutical, cosmetic, and food industries. For example, ethanolic extract can protect raw or cooked meat [25]. Chlorogenic and gallic acids were the most common 
phenolics in roasted coffee and SCGs, contributing to $80 \%$ of the total phenolics $[8,26]$. The yield and kind of bioactive components recovered from the SCGs are defined according to coffee species, extraction method, storage conditions, and instant-coffee manufacturing efficiency. Increased coffee roasting intensity (from medium to dark) reduced the phenolic acids of chlorogenic $(6 \%)$, gallic $(15 \%)$, p-coumaric $(33 \%)$, ferulic $(14 \%)$, quercetin $(14 \%)$, and catechin $(60 \%)$ due to isomerization. At the same time, this treatment increased ellagic acid (50\%) without affecting caffeic acid and rutin contents [8].

The present extract was richer in flavonoid compounds than the previous investigations of different extraction systems. Four flavonoids have been identified in the SCGs using ethanol and microwave extraction techniques: epicatechin, catechin, rutin, and quercetin [8]. However, in the present extract, there were eight flavonoids recorded. Flavonoids own several health functions and elicited protective effects, including anti-inflammatory, antioxidant, antiviral, and anti-carcinogenic effects. Recently, apigenin has spurred interest due to its low intrinsic toxicity and antidiabetic and anti-inflammatory activities. Apigenin7-glucoside showed higher antifungal activity on Candida and cytotoxic effect on colon cancer cells than apigenin [27]. In turn, naringenin has been reported to exhibit antioxidant activity [28].

Caffeine is one of the essential bioactive components found in SCGs in a remarkable concentration (Table 1), consistent with Kovalcik et al. [6]. It can exert many biological activities such as the possible link to depression by reducing pro-inflammatory mediators tumor necrosis factor alpha (TNF- $\alpha$ ), Interleukin- $1 \beta$ (IL-1 $\beta$ ), Interleukin-6 (IL-6), and interferon-c (IFNc), probably via the Jun N-terminal kinase (JNK1/2) and p 38 mitogenactivated protein kinases (p 38 MAPK) signaling pathway [29]. Some antifungal agents have been drug-resistant [22,23]. New antifungal compounds or better alternatives should be discovered to increase treatment efficacy against toxigenic fungus infection. In this regard, antifungal agents derived from natural resources, such as phenolic compounds, provide an alternative strategy for addressing developing antifungal drug tolerance [24]. Many of these compounds possess antimicrobial effects [30,31]. The mechanism of phenolic compounds to inhibit microbial contamination is linked mainly to the antioxidant potency possessed by the phenolic extract [32].

Concerning the results, the SCG possessed better antifungal potency, making it qualified to decrease the contamination by toxigenic fungi where it exists (Figures 2 and 3). Moreover, the toxins which these strains of fungi could secrete were recorded limited or degraded if the extract was present in their growth media (Table 3). The mycotoxin reduction compared to the control displayed the interaction of the SCGs extract's constituents with the growth factors of toxigenic fungi. These developments, which occurred in the media content through the extracts' existence, lead to toxin secretion reduction [33]. The AFs are a family of health-hazard chemicals generated from polypeptides [34]. More than 20 genes grouped in the DNA sequence area must be synthesized. As transcription agents, the genes encode various enzymes involved in toxin production [35]. The mechanism by which the reduction happened to aflatoxins secretion proposed a link to gene docking between genes of aflatoxin production in the fungal cell and polyphenol compounds.

Several prior studies have looked at the effect of plant phytochemicals on toxigenic fungi's aflatoxin gene cluster and the aflatoxin biosynthesis pathway. Phytochemicals such as phenolic acids are also known to inhibit gene expression in the aflatoxin pathway $[18,36]$. Furthermore, plant phytochemicals play a key role in toxigenic fungus gene regulation [20,37]. In the same ways, and where Ochratoxin A is produced by another Aspergillus fungal strain, the mechanism of ochratoxin reduction in media could be linked to the extract's contents of bioactive phenols. This suggestion led the authors to investigate the extract efficacy even when the food products are contaminated by ochratoxin. Forward of this, the application of the SCGs extract in food products containing spiked ochratoxin resulted in safer properties, where the extract recorded a reduction impact in synthetic media (Table 4). The spiked-ochratoxin reduction in a simulated food model shows the extract's effectiveness as a safety agent that could be processed for the safety properties 
of the final product. The reduction recorded for toxin production in media, which was noticed for the results in Table 3, could be elucidated through the phytochemical impact on the toxin gene regulation [38].

In agreement with our results, Gigliobianco et al. [39], found that the cytotoxicity of aqueous SCGs extract at $80{ }^{\circ} \mathrm{C}$ in keratinocyte $\mathrm{HaCaT}$ cells was ineffective on cell viability at concentrations lower than $3 \mathrm{mg} / \mathrm{mL}$. Coffee and its spent grounds contain many bioactive constituents that affect the human body, such as caffeine, caffeic acid, chlorogenic acids, trigonelline, diterpenes, and melanoidins. Some have demonstrated potential anticarcinogenic effects in animal models and human cell cultures and may play a protective role against many types of cancer such as colorectal cancer [40].

\section{Conclusions}

The current study encourages researchers to exploit waste from food, such as SCGs, which are commonly trashed, to produce extracts with added values. Concerning the promising bioactive phenolics and flavonoids components obtained, the anti-mycotoxigenic impact and the cytotoxicity of SCGs isopropanol extract were evaluated during the current study, along with a simulation experiment for ochratoxin reduction in brownies. Phenolic compounds have well-known bioactivity against oxidative stress caused by mycotoxin contamination, in addition to the caffeine, which positively reduced ochratoxin reduction. In agreement with the above facts, the extract was shown by an antifungal effect applied in diffusion assays against toxigenic fungal strains, especially A. flavus and A. ochraceus. The extract is more efficient for the anti-Fusarium followed by the anti-ochraceus fungi activity. Therefore, SCGs could be applied in food products to reduce the mycotoxin contamination of raw materials to the acceptable regulated limits. Additionally, the examined extract's moderate cytotoxic and antibacterial activities represent a business opportunity to have nutraceutical foods with healthy functions.

\section{Materials and Methods}

\subsection{Materials, Chemicals, and Microorganisms}

Spent coffee was gifted to the research team as a free sample from Misr Coffee (10th. of Ramadan Ind. City, Cairo, Egypt Industrial Company). The powder was milled to a close micronize granules ( $40 \mathrm{mesh}$ ) for the extraction and application steps. The powder was immediately dried $\left(38 \pm 2{ }^{\circ} \mathrm{C}\right)$ using a Hot-air oven (Model ED 56, Binder GmbH, 78532 Tuttlingen, Germany) until it was completely dried.

Six strains of bacteria including Staphylococcus aureus ATCC 33591, Bacillus cereus ATCC 11778, Klebsiellapneumoniae ATCC 27736, Escherichia coli ATCC 11229, Pseudomonas aeruginosa ATCC 9721, and Salmonella typhi ATCC 14028 were applied for the antibacterial assay. Antifungal assay was determined against the fungi strains of A. flavus item 698, A. ochraceus item 7043, A. niger item 9568, Penicillium chrysogenum ATCC 10106, F. culmorum KF 846, and F. verticillioides FM 19.

\subsection{Preparation of Spent Coffee Extract}

Isopropanol extraction assay was applied to gain the SCGs bioactive components following the methodology described by Abdel-Salam et al. [41], with modifications. A contentious system using a peristaltic pump (Model S300-12B, Baoding Ditron Electronic Technology Co., Baoding, China) with a filter, connected to a horizontal-double jacket basin containing the powder of spent coffee submerged in aqueous isopropanol (80\%) at $40{ }^{\circ} \mathrm{C} / 4 \mathrm{~h}$ was used. The gained extract was collected after the end process, concentrated to known volume using a rotary evaporator (Heidolph, HeiVAP, GmbH, Landsberger, Germany), and was then was kept in an amber bottle for further analyses and applications.

\subsection{Determination of Phenolic Acids and Flavonoids}

The analysis was performed using an Acquity $\mathrm{H}$ class UPLC system equipped with a Waters Acquity PDA detector (Waters, Milford, MD, USA). The condition and the column 
characteristics were the same as described by Stuper-Szablewska et al. [42]. As the eluent for the chromatographic separation, a solution of acetonitrile: $2 \%$ acetic acid in water $(\mathrm{pH}=2)$ was utilized (gradient). External standards were used to detect the concentrations of phenolic acids at $=320$ and $280 \mathrm{~nm}$, and the detection limit was $1 \mu \mathrm{g}$. It was possible to determine the existence of certain substances by matching the retention times of examined peaks to those of standard references and then conducting further analyses using a smaller volume of the standard added with the estimated samples.

\subsection{Determination of Antibacterial and Antifungal Effects}

The antimicrobial activity of the spent coffee extract was determined by measuring the diffusion assays according to the methodology of Abdel Razek et al. [43]. Applied strains of bacteria were reactivated from lyophilized stocks on Tryptic soy broth media. The activated strains were spread on Tryptic soy agar plates, the disks or wells were loaded using $100 \mu \mathrm{L}$ of spent extract. The impact of applied extract for the inhibition was recorded as clear zone diameter $(\mathrm{mm})$ for each strain: the greater the inhibition zone diameter, the more effective the concentration. The antifungal effect was determined against the fungal strains cultured on Czapek-dox agar media, where the disk and well diffusion assays were applied using isopropanol SCGs extract.

\subsection{Determination of SCGs Cytotoxic Effect Using the Tetrazolium-Based (MTT) Assay}

Human liver cancer (HepG2) and human healthy oral epithelial (OEC) cell lines were cultured at a density of $1 \times 10^{4}$ cells/well $(100 \mu \mathrm{L})$ in a culture medium of the Dulbecco's Modified Eagle Medium (DMEM) supplemented with antibiotics (10,000 U of penicillin and $10 \mathrm{mg}$ of streptomycin in $0.9 \%$ saline) and $10 \%$ serum of the phosphate buffer saline (PBS). They were then incubated for $24 \mathrm{~h}$ at $37{ }^{\circ} \mathrm{C}$ and $5 \% \mathrm{CO}_{2}$. After attachment for $24 \mathrm{~h}$, a serially diluted extract was applied at concentrations ranging from 1000 to $0.01 \mu \mathrm{g} / \mathrm{mL}$ for OEC and from 200 to $0.01 \mu \mathrm{g} / \mathrm{mL}$ for HepG2 cells. As parallel, a positive control (Cisplatin) at concentrations ranging from 400 to $0.01 \mu \mathrm{g} / \mathrm{mL}$ was applied. Subsequently, $10 \mu \mathrm{L}$ of a 12-mM MTT stock solution (5 mg/mL MTT in sterile PBS) was added to each well. After incubation for $4 \mathrm{~h}$ at $37^{\circ} \mathrm{C}$, the MTT solution was eliminated, and the precipitated purple formazan crystal was dissolved in dimethyl-sulphoxide (DMSO) for $20 \mathrm{~min}$. Negative control of $10 \mu \mathrm{L}$ of the MTT stock solution was added to $100 \mu \mathrm{L}$ of an uncultured medium. The absorbance was measured at $540 \mathrm{~nm}$ using a BMG LABTECH ${ }^{\circledR}$ - FLUOstar Omega microplate reader (Ortenberg, Germany). The absorbance was measured at $570 \mathrm{~nm}$.

$$
\left[\left(\mathrm{OD}_{\text {sample }}-\mathrm{OD}_{\text {blank }}\right) /\left(\mathrm{OD}_{\text {control }}-\mathrm{OD}_{\text {blank }}\right) \times 100 \%\right]
$$

where; OD sample: optical density of the sample.

OD blank: optical density of the blank (DMSO).

OD control: optical density of the control.

The curve was illustrated based on the variation of the proportions of surviving cells according to concentrations, and $\mathrm{IC}_{50}$ was calculated using a sigmoidal curve obtained [44].

\subsection{Determination of the SCGs Cytotoxic Effect Using Sulforhodamine B (SRB) Assay}

The cytotoxic activity of the extract was assessed again by SRB assay against HepG2 and OEC cell lines. Aliquots of $100 \mu \mathrm{L}$ cell suspension $\left(5 \times 10^{3}\right.$ cells $)$ were placed in 96-well plates and incubated in complete media for $24 \mathrm{~h}$. Cells were treated with another aliquot of $100 \mu \mathrm{L}$ media containing the extract or the positive control (Cisplatin) at various concentrations ranging from $0.01-1000 \mu \mathrm{g} / \mathrm{mL}$. After $72 \mathrm{~h}$ of drug exposure, cells were fixed by replacing media with $150 \mu \mathrm{L}$ of $10 \%$ TCA and incubated at $4{ }^{\circ} \mathrm{C}$ for $1 \mathrm{~h}$. The trichloroacetic acid solution (TCA) solution was removed, and the cells were washed five times with distilled water. Aliquots of $70 \mu \mathrm{L}$ SRB solution $(0.4 \% w / v)$ were added and incubated in a dark place at room temperature for $10 \mathrm{~min}$. Plates were washed three times with $1 \%$ acetic acid and air-dried overnight. Then, $150 \mu \mathrm{L}$ of $10 \mathrm{mM}$ trisaminomethane 
(TRIS) was added to dissolve the protein-bound SRB stain; the absorbance was measured at $540 \mathrm{~nm}$ using a BMG LABTECH ${ }^{\circledR}$ - FLUOstar Omega microplate reader (Ortenberg, Germany) [45].

\subsection{Selectivity Index (SI)}

Selectivity index (SI) is a ratio of the toxic concentration of a sample against its effective bioactive concentration. The higher ratio of SI represents a more effective and safer drug when used during in vivo treatment [46]. The following equation evaluated the SI value:

$$
\mathrm{SI}=\mathrm{IC}_{50} \text { No cancer cell } / \mathrm{IC}_{50} \text { Cancer cell }
$$

\subsection{Simulated Experiment to Evaluate the Anti-Mycotoxigenic Impact}

The influence of the SCGs extract against toxigenic fungal strains (A. flavus ITEM 698 and $A$. ochraceus ITEM 7043) was determined. The expected inhibition for fungal growth and toxin reduction of these known strain-producing fungi was evaluated at several concentrations $\left(0.5,1,1.5,2 \mathrm{mg}\right.$ extract $/ 100 \mathrm{~mL}$ media). The $10^{5}$ spore $/ \mathrm{mL}$ concentration was suspended in a $1 \mathrm{~L}$ conical flask containing $250 \mathrm{~mL}$ yeast extract sucrose (YES). The flasks of control (SCGs-free) and treatments were incubated (5 days $/ 22{ }^{\circ} \mathrm{C}$ for growth change evaluations and 12 days $/ 28^{\circ} \mathrm{C}$ for toxin production changes). The experiment was performed in triplicate and statistically evaluated.

\subsection{Application of Spent Coffee in Brownies for Ochratoxin A Evaluation}

A ready-made powder for cookies was purchased for preparing a food model. Such a model was utilized for evaluating spiked-OCA reduction that linked to SCGs-fortification. Five ratios were designed to assess the fortifications impact as 1, 3, 5, 7, and 10\% of the SCGs added to the recipe. The spiked cookies (+ve control), the control (-ve control), and fortified samples (treatments) were evaluated at $(0,2 \mathrm{~h}$, and $4 \mathrm{~h})$ of dough incubation and after cooking. The OCA reduction is directly proportional to the SCGs' effective ratio of fortification. The samples were taken in triplicate and analyzed statistically.

\subsection{Mycotoxin Determination}

High-performance liquid chromatography, Agilent 1100 (Agilent Technologies, HewlettPackard Strasse 876,337 Waldbronn, Germany), was utilized for the AFs and OCA determination. The AFs mobile phase was water: acetonitrile: methanol (6:3:1). The chromatographic separation was performed with an Extend-C18, Zorbax column $(250 \mathrm{~mm} \times 5 \mathrm{~mm}$; $46 \mu \mathrm{m}$, Agilent Co., Santa Clara, CA, USA). The column temperature was $40^{\circ} \mathrm{C}$, and the flow rate was $1.0 \mathrm{~mL} / \mathrm{min}$; the injection volume was $20 \mu \mathrm{L}$ for samples and standard. The detector was adjusted at 360/440 nm for the excitation and the emission wavelength, respectively. Data were integrated and recorded using a Chem-Station software Manager Hewlett-Packard (Agilent Co., Santa Clara, CA, USA). The OCA was extracted and evaluated from the media, similar to the methodology of Badr et al. [47]. The OCA mobile phase was a mixture of acetonitrile: water: methanol $(46: 46: 8, v / v)$, and the flow rate was $1.0 \mathrm{~mL} / \mathrm{min}$. The OCA quantification was performed by comparing the retention time against the standard. The OCA identity was confirmed at 274 and $440 \mathrm{~nm}$ for excitation and emission wavelengths, respectively, compared to the OCA peak of the standard. The injection volume was $20 \mu \mathrm{L}$, and the retention time was approximately $11 \mathrm{~min}$. The analysis has a detection limit of $0.01 \mu \mathrm{g} / \mathrm{g}$. A computing integrator (Millenium-32v., 3.05) was utilized to compare the peak area with the proper standard curve, which resulted in an accurate measurement.

\subsection{Statistical Analysis}

The results were expressed as means \pm standard deviation (SD) of at least three replicates. The analysis of variance (ANOVA) was used to assess the significant difference between the mean values, and Duncan's multiple range test was calculated $(p=0.05)$. The 
statistical data analyses were performed using Graph Pad Prism 7 (Graph Pad Software Inc., San Diego, CA, USA).

Author Contributions: Conceptualization, A.N.B., H.S.A. and A.F.; data curation, M.F.E., A.F. and H.M.Y.; formal analysis, A.N.B., M.M.E.-A. and A.F.; funding acquisition, M.F.E.; investigation, A.N.B., M.M.E.-A., M.F.E. and A.F.; methodology, A.N.B., H.S.A. and A.F.; project administration, H.S.A., H.M.Y. and M.F.E.; resources, H.M.Y. and A.F.; software, M.M.E.-A., H.S.A. and A.N.B.; supervision, M.F.E. and A.F.; validation, A.N.B., M.M.E.-A. and A.F.; visualization, A.N.B., M.M.E.-A. and H.S.A.; writing—original draft, A.F.; writing—review and editing, A.N.B. All authors have read and agreed to the published version of the manuscript.

Funding: Princess Nourah bint Abdulrahman Project Number (PNURSP2020R23).

Institutional Review Board Statement: Not applicable.

Informed Consent Statement: Not applicable.

Data Availability Statement: All the data regarding this work were represented inside this manuscript.

Acknowledgments: Princess Nourah bint Abdulrahman University, Researchers Supporting Project Number (PNURSP2022R23), Princess Nourah bint Abdulrahman University, Riyadh 11564, Saudi Arabia.

Conflicts of Interest: The authors declare no conflict of interest.

\section{References}

1. Ghosh, P.R.; Fawcett, D.; Sharma, S.B.; Poinern, G.E.J. Progress towards Sustainable Utilization and Management of Food Wastes in the Global Economy. Int. J. Food Sci. 2016, 2016, 3563478. [CrossRef]

2. Adejumo, I.O.; Adebiyi, O.A. Agricultural Solid Wastes: Causes, Effects, and Effective Management. In Strategies of Sustainable Solid Waste Management; Saleh, H., Ed.; IntechOpen: London, UK, 2021; pp. 1-19. [CrossRef]

3. Wu, C.-T.; Agrawal, D.C.; Huang, W.-Y.; Hsu, H.-C.; Yang, S.-J.; Huang, S.-L.; Lin, Y.-S. Functionality Analysis of Spent Coffee Ground Extracts Obtained by the Hydrothermal Method. J. Chem. 2019, 2019, 4671438. [CrossRef]

4. ICO. ICO, the Coffee Market Report, in Monthly Coffee Market Report (2021/22); ICO: London, UK, 2021; pp. 1-9. Available online: https:/ /www.ico.org/trade_statistics.asp (accessed on 28 February 2021).

5. Mitraka, G.-C.; Kontogiannopoulos, K.N.; Batsioula, M.; Banias, G.F.; Assimopoulou, A.N. Spent Coffee Grounds' Valorization towards the Recovery of Caffeine and Chlorogenic Acid: A Response Surface Methodology Approach. Sustainability 2021, 13, 8818. [CrossRef]

6. Kovalcik, A.; Obruca, S.; Marova, I. Valorization of spent coffee grounds: A review. Food Bioprod. Processing 2018, 110, 104-119. [CrossRef]

7. Mussatto, S.I.; Ballesteros, L.F.; Martins, S.; Teixeira, J.A. Extraction of antioxidant phenolic compounds from spent coffee grounds. Sep. Purif. Technol. 2011, 83, 173-179. [CrossRef]

8. López-Barrera, D.M.; Vázquez-Sánchez, K.; Loarca-Piña, M.G.F.; Campos-Vega, R. Spent coffee grounds, an innovative source of colonic fermentable compounds, inhibit inflammatory mediators in vitro. Food Chem. 2016, 212, 282-290. [CrossRef]

9. Huang, H.-C.; Wei, C.-M.; Siao, J.-H.; Tsai, T.-C.; Ko, W.-P.; Chang, K.-J.; Hii, C.-H.; Chang, T.-M. Supercritical Fluid Extract of Spent Coffee Grounds Attenuates Melanogenesis through Downregulation of the PKA, PI3K/Akt, and MAPK Signaling Pathways. eCAM 2016, 2016, 5860296. [CrossRef]

10. Liu, C.; Pujo, D.; Olivella, M.À.; de la Torre, F.; Fiol, N.; Poch, J.; Villaescusa, I. The Role of Exhausted Coffee Compounds on Metal Ions Sorption. Water Air Soil Pollut. 2015, 226, 289. [CrossRef]

11. Seo, H.S.; Park, B.H. Phenolic compound extraction from spent coffee grounds for antioxidant recovery. Korean J. Chem. Eng. 2019, 36, 186-190. [CrossRef]

12. Karahalil, E. Principles of halal-compliant fermentations: Microbial alternatives for the halal food industry. Trends Food Sci. Technol. 2020, 98, 1-9. [CrossRef]

13. Khoddami, A.; Wilke, M.A.; Robert, T.H. Techniques for Analysis of Plant Phenolic Compounds. Molecules 2013, 18, 2328 [CrossRef]

14. Teodoro, G.R.; Ellepola, K.; Seneviratne, C.J.; Koga-Ito, C.Y. Potential Use of Phenolic Acids as Anti-Candida Agents: A Review. Front. Microbiol. 2015, 6, 1420. [CrossRef]

15. Evensen, N.A.; Braun, P.C. The effects of tea polyphenols on Candida albicans: Inhibition of biofilm formation and proteasome inactivation. Can. J. Microbiol. 2009, 55, 1033-1039. [CrossRef]

16. Shahzad, M.; Sherry, L.; Rajendran, R.; Edwards, C.A.; Combet, E.; Ramage, G. Utilizing polyphenols for the clinical management of Candida albicans biofilms. Int. J. Antimicrob. Agents 2014, 44, 269-273. [CrossRef]

17. Powers, C.N.; Satyal, P.; Mayo, J.A.; McFeeters, H.; McFeeters, R.L. Bigger Data Approach to Analysis of Essential Oils and Their Antifungal Activity against Aspergillus niger, Candida albicans, and Cryptococcus Neoformans. Molecules 2019, 24, 2868. [CrossRef] 
18. Makhuvele, R.; Naidu, K.; Gbashi, S.; Thipe, V.C.; Adebo, O.A.; Njobeh, P.B. The use of plant extracts and their phytochemicals for control of toxigenic fungi and mycotoxins. Heliyon 2020, 6, e05291. [CrossRef]

19. Wu, Q.; Wang, X.; Nepovimova, E.; Wang, Y.; Yang, H.; Li, L.; Zhang, X.; Kuca, K. Antioxidant agents against trichothecenes: New hints for oxidative stress treatment. Oncotarget 2017, 8, 110708-110726. [CrossRef]

20. Loi, M.; Paciolla, C.; Logrieco, A.F.; Mulè, G. Plant Bioactive Compounds in Pre- and Postharvest Management for Aflatoxins Reduction. Front. Microbiol. 2020, 11, 243. [CrossRef]

21. Wong, S.S.W.; Kao, R.Y.T.; Yuen, K.Y.; Wang, Y.; Yang, D.; Samaranayake, L.P.; Seneviratne, C.J. In Vitro and In Vivo Activity of a Novel Antifungal Small Molecule against Candida Infections. PLoS ONE 2014, 9, e85836. [CrossRef]

22. Ben-Ami, R.; Garcia-Effron, G.; Lewis, R.E.; Gamarra, S.; Leventakos, K.; Perlin, D.S.; Kontoyiannis, D.P. Fitness and Virulence Costs of Candida albicans FKS1 Hot Spot Mutations Associated with Echinocandin Resistance. J. Infect. Dis. 2011, 204, 626-635. [CrossRef]

23. Clancy, C.J.; Nguyen, M.H. At What Cost Echinocandin Resistance? J. Infect. Dis. 2011, 204, 499-501. [CrossRef] [PubMed]

24. Negri, M.; Salci, T.P.; Shinobu-Mesquita, C.S.; Capoci, I.R.G.; Svidzinski, T.I.E.; Kioshima, E.S. Early State Research on Antifungal Natural Products. Molecules 2014, 19, 2925-2956. [CrossRef]

25. Kim, J.-H.; Ahn, D.U.; Eu, J.B.; Moo, S.H. Antioxidant Effect of Extracts from the Coffee Residue in Raw and Cooked Meat. Antioxidants 2016, 5, 21. [CrossRef] [PubMed]

26. Murthy, P.S.; Naidu, M.M. Recovery of Phenolic Antioxidants and Functional Compounds from Coffee Industry By-Products Food Bioprocess Technol. 2012, 5, 897-903. [CrossRef]

27. Smiljkovic, M.; Stanisavljevic, D.; Stojkovic, D.; Petrovic, I.; Vicentic, J.M.; Popovic, J.; Grdadolnik, S.G.; Markovic, D.; SankovicBabice, S.; Glamoclija, J.; et al. Apigenin-7-O-glucoside versus apigenin: Insight into the modes of anticandidal and cytotoxic actions. EXCLI J. 2017, 16, 795-807. [CrossRef] [PubMed]

28. Güez, C.M.; de Souza, R.O.; Fischer, P.; Leão, M.F.M.; Duarte, J.A.; Boligon, A.A.; Athayd, M.L.; Zuravsk, L.; de Oliveir, L.F.S.; Machado, M.M. Evaluation of basil extract (Ocimum basilicum L.) on oxidative, anti-genotoxic, and anti-inflammatory effects in human leukocytes cell cultures exposed to challenging agents. Braz. J. Pharm. Sci. 2017, 53, e15098. [CrossRef]

29. Hall, S.; Desbrow, B.; Anoopkumar-Dukie, S.; Davey, A.K.; Arora, D.; McDermott, C.; Schubert, M.M.; Perkins, A.V.; Kiefel, M.J.; Grant, G.D. A review of the bioactivity of coffee, caffeine and key coffee constituents on inflammatory responses linked to depression. Food Res. Int. 2015, 76, 626-636. [CrossRef] [PubMed]

30. Liu, J.; Du, C.; Beaman, H.T.; Monroe, M.B.B. Characterization of Phenolic Acid Antimicrobial and Antioxidant Structure-Property Relationships. Pharmaceutics 2020, 12, 419. [CrossRef]

31. Ouerghemmi, I.; Rebey, I.B.; Rahali, F.Z.; Bourgou, S.; Pistelli, L.; Ksouri, R.; Marzouk, B.; Tounsi, M.S. Antioxidant and antimicrobial phenolic compounds from extracts of cultivated and wild-grown Tunisian Ruta chalepensis. J. Food Drug Anal. 2017, 25, 350-359. [CrossRef]

32. Mandal, S.M.; Dias, R.O.; Franco, O.L. Phenolic Compounds in Antimicrobial Therapy. J. Med. Food 2017, 20, 1031-1038. [CrossRef]

33. Badr, A.N.; Ali, H.S.; Abdel-Razek, A.G.; Shehata, M.G.; Albaridi, N.A. Bioactive Components of Pomegranate Oil and Their Influence on Mycotoxin Secretion. Toxins 2020, 12, 748. [CrossRef] [PubMed]

34. Shahat, M.S.; Badr, A.N.; Hegaziy, A.I.; Ramzy, S.; Samie, M.A. Reducing the histopathological and biochemical toxicity of aflatoxins contaminated soybean using ozone treatment. Ann. Res. Rev. Biol. 2017, 15, 1-10. [CrossRef]

35. Yu, J.J. Genetics and biochemistry of mycotoxin synthesis. Fungal Biotechnol. Agric. Food Environ. Appl. 2004, 2004, $343-361$.

36. Safari, N.; Ardakani, M.M.; Hemmati, R.; Parroni, A.; Beccaccioli, M.; Reverberi, M. The Potential of Plant-Based Bioactive Compounds on Inhibition of Aflatoxin $B_{1}$ Biosynthesis and Down-regulation of aflR, aflM, and aflP Genes. Antibiotics 2020, 9, 728. [CrossRef] [PubMed]

37. Mahoney, N.; Molyneux, R.J. Phytochemical Inhibition of Aflatoxigenicity in Aspergillus flavus by Constituents of Walnut (Juglans regia). J. Agri. Food Chem. 2004, 52, 1882-1889. [CrossRef] [PubMed]

38. Abdel-Razek, A.G.; Badr, A.N.; Alharthi, S.S.; Selim, K.A. Efficacy of Bottle Gourd Seeds' Extracts in Chemical Hazard Reduction Secreted as Toxigenic Fungi Metabolites. Toxins 2021, 13, 789. [CrossRef] [PubMed]

39. Gigliobianco, M.R.; Campisi, B.; Peregrina, D.V.; Censi, R.; Khamitova, G.; Angeloni, S.; Caprioli, G.; Zannotti, M.; Ferraro, S.; Giovannetti, R.; et al. Optimization of the Extraction from Spent Coffee Grounds Using the Desirability Approach. Antioxidants 2020, 9, 370. [CrossRef] [PubMed]

40. Bułdak, R.J.; Hejmo, T.; Osowski, M.; Bułdak, Ł.; Kukl, M.; Polania, R.; Birkner, E. The Impact of Coffee and Its Selected Bioactive Compounds on the Development and Progression of Colorectal Cancer In Vivo and In Vitro. Molecules 2018, 23, 3309. [CrossRef] [PubMed]

41. Abdel-Salam, A.M.; ABadr, N.; Zaghloul, A.H.; Farrag, A.R.H. Functional yogurt aims to protect against the aflatoxin B1 toxicity in rats. Toxicol. Rep. 2020, 7, 1412-1420. [CrossRef] [PubMed]

42. Stuper-Szablewska, K.; Kurasiak-Popowska, D.; Nawracała, J.; Perkowski, J. Response of non-enzymatic antioxidative mechanisms to stress caused by infection with Fusarium fungi and chemical protection in different wheat genotypes. Chem. Ecol. 2017, 33, 949-962. [CrossRef]

43. Abdel-Razek, A.G.; Badr, A.N.; El-Messery, T.M.; El-Said, M.M.; Hussein, A.M.S. Micro-nano encapsulation of black seed oil ameliorate its characteristics and its mycotoxin inhibition. Biosci. Res. 2018, 15, 2591-2601. 
44. Aouf, A.; Ali, H.; Al-Khalifa, A.R.; Mahmoud, K.F.; Farouk, A. Influence of Nanoencapsulation Using High-Pressure Homogenization on the Volatile Constituents and Anticancer and Antioxidant Activities of Algerian Saccocalyx satureioides Coss. et Durieu. Molecules 2020, 25, 4756. [CrossRef] [PubMed]

45. El-Massry, K.F.; Farouk, A.; Mahmoud, K.F.; El-Ghorab, A.H.; M, S.S.; Musa, A.; Mostafa, E.M.; Ghoneim, M.M.; Naguib, I.A.; Abdelgawad, M.A. Chemical characteristics and targeted encapsulated Cordia myxa fruits extracts nanoparticles for antioxidant and cytotoxicity potentials. Saudi J. Biol. Sci. 2021, 28, 5349-5358. [CrossRef] [PubMed]

46. Pritchett, J.C.; Naesens, L.; Montoya, J. Treating HHV-6 Infections: The Laboratory Efficacy and Clinical Use of Anti-HHV-6 Agents. In Human Herpesviruses HHV-6A, HHV-6B \& HHV-7, 3rd ed.; Flamand, L., Lautenschlager, I., Krueger, G., Ablashi, D., Eds.; Elsevier: Boston, MA, USA, 2014; pp. 311-331. [CrossRef]

47. Badr, A.N.; Gromadzka, K.; Shehata, M.G.; Stuper-Szablewska, K.; Drzewiecka, K.; Abdel-Razek, A.G.; Youssef, M.M. Encapsulated Bioactive Ingredients of grape by-products applicate in fresh-cut fruit and juices diminished the ochratoxins. J. Food Process. Preserv. 2021, 45, e15112. [CrossRef] 